\title{
Research on Supercapacitor Charging Efficiency of Photovoltaic System
}

\author{
ZhangJinlong, WangJiuhe, WuXibao \\ School of Automation \\ Beijing Information Science \& Technology University, BISTU \\ Beijing, China \\ Email: zj1@bistu.edu.cn, zhangj12004@163.com
}

\begin{abstract}
-the model of supercapacitor and its charging performance with constant voltage charging mode, constant current charging mode and constant power charging mode were studied. A numerical method to calculate the efficiency of these charging modes was inducted. To analyze the storage performance of supercapacitor in PV system, using this method, the maximum charging efficiencies of supercapacitor when its terminal voltage raise from zero to the rated voltage with different charging modes were presented. The multi-stage charging efficiency curves were retrieved, which indicated that the constant power charging mode is more suitable when supercapacitor are charged in PV system. A MPPT plus constant power control charging strategy using two-stage Buck-Boost converter to charge supercapacitor in PV system was proposed. The simulation results showed that this strategy effectively ensure the charging efficiency of the system.
\end{abstract}

Keywords-supercapacitor; charging efficiency; maximum power point track; constant power charging; photovoltaic system

\section{INTRODUCTION}

How to improve energy efficiency of power supplies by utilizing energy storage systems has always been a key consideration, as in [1] [2] [3] [4]. Where energy is supplied by renewable energy, such as PV cells, energy storage system plays important roles in smoothing power and supplying energy at night, as in [5] [6] [7].

The output power of solar cells array varies with light intensity, environmental temperature and output voltage. However, there is a unique Maximum Power Point (MPP) under a certain light intensity and ambient temperature, as in [8]. The output power and output voltage of solar cells are determined by output current. Therefore the maximum output power can be achieved by changing output current dynamically in Maximum Power Point Track (MPPT) control mode.

MPPT is generally realized by single-stage DC/DC converter that paralleled with PV cells. However, the output DC voltage of converter would vary in a range dynamically. As the output voltage is uncontrollable, when supercapacitor is charging, there is big difference between the supercapacitor voltage and output DC voltage. For example, during the initial charge period, a large of power would be consumed by equivalent series resistance (ESR) in supercapacitor, and the charging efficiency would be very low in this respect, as in [9].

This work is supported by Beijing Municipal Commission of education science and technology plan projects (No. KM201010772010), (No. KM201010772009), Funding Project for Academic Human Resources Development in Institutions of Higher Learning Under the Jurisdiction of Beijing Municipality (No.PHR201108262) and Funding Project for Academic Human Resources Development in Institutions of Higher Learning Under the Jurisdiction of Beijing Municipality(No.PHR201007130).
As a result, it is necessary to numerically analyze the charging efficiency of supercapacitor in PV system by using different charging modes, and then, an appropriate charging control algorithm can be obtained and can then be realized in converters.

\section{ANALYSIS ON CHARGING EFFICIENCY}

It is particularly important to control charging efficiency, because the source of energy is unstable and the output power is limited when supercapacitor is charged by renewable energy such as solar or wind energy source. PV system is not able to supply consistent charging current due to power limit of PV cells. Under such condition, the charging efficiency should not be determined by the charging current, while charging circuit allows supercapacitor to store most of the power generated by PV cells. Therefore, it is critical to have a numerical analysis on charging efficiency of supercapacitor in PV system in different charging modes.

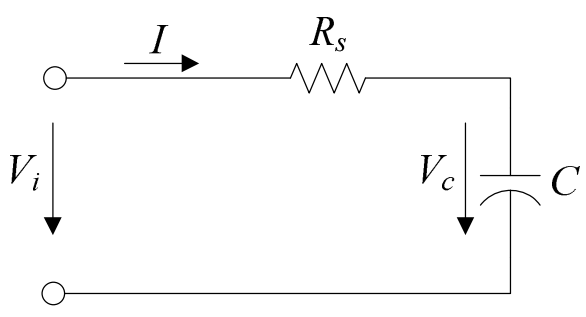

Figure 1. Supercapacitor equivalent charging circuit

The charging circuit of supercapacitor under series connection RC model is shown in Fig.1, where $C$ is an ideal supercapacitor, $R_{\mathrm{s}}$ is an ESR, $V_{\mathrm{i}}$ is input charging voltage, $I$ is charging current, and $V_{\mathrm{c}}$ is supercapacitor voltage. From Fig.1, it can be obtained, as the following:

$$
\begin{gathered}
V_{i}=V_{c}+I R_{s} . \\
I=C \frac{d V_{c}}{d t} .
\end{gathered}
$$

The charging efficiency $\eta$ is determined by the energy conserved by supercapacitor and transmitted by the charging circuit. The $\eta$ can be defined as: 


$$
\eta=\frac{E_{c}}{E_{t}} .
$$

In constant voltage charging mode (CVCM), the math model of capacitor voltage is obtained by using complete response of the circuit, where $V_{\mathrm{c} 0}$ refers to the initial value of supercapacitor voltage:

$$
v_{c}(t)=\left(V_{c 0}-V_{i}\right) e^{-\frac{t}{R_{s} C}}+V_{i} .
$$

From (2), (3) and (4), when $V_{\mathrm{c} 0}=0$, the charging efficiency in CVCM can be written, as in

$$
\eta=\frac{E_{c}}{E_{t}}=\frac{1}{2}\left(1-e^{-\frac{T}{R_{s} C}}\right) .
$$

It is show that in CVCM, when $V_{\mathrm{c} 0}=0$, the charging efficiency increases with the elapsed charging time, but it is up to a maximum rate of $50 \%$.

The rise rate of supercapacitor voltage remains constant too, i.e. I/C in CVCM, because the charging current $I$ is constant, according to (2). The supercapacitor voltage therefore can be expressed, as in

$$
v_{c}(t)=\frac{I}{C} t+V_{c 0}
$$

The relationship between the charging time $T$ and supercapacitor voltage can be shown, as in

$$
T=\frac{C\left(V_{c T}-V_{c 0}\right)}{I} \text {. }
$$

From (3), (6) and (7), the charging efficiency $\eta$ in CVCM can then be expressed, as in

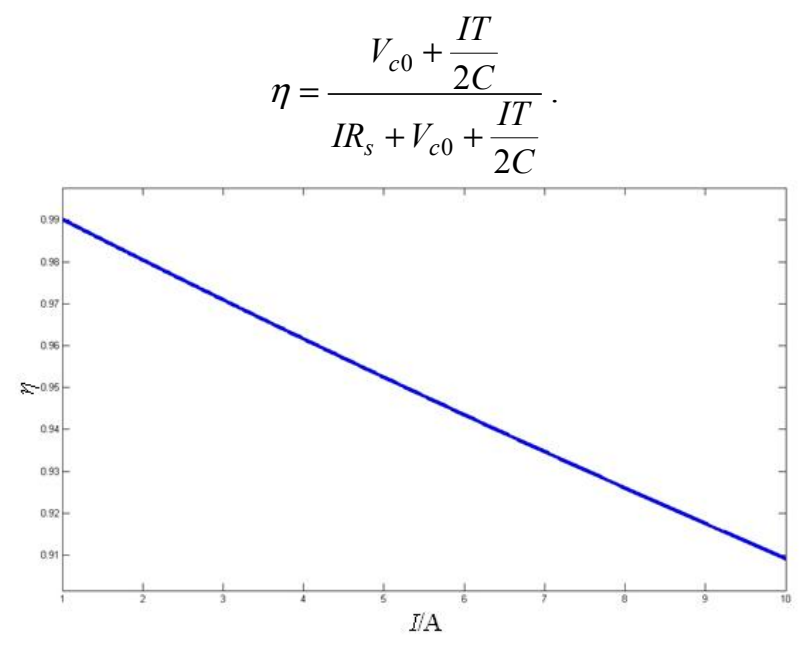

Figure 2. The relationship between the charging efficiency and the charging current

It is shown that in CVCM the charging efficiency is dependent on the values of charging current $I$ and ESR $R_{s}$. Assuming $V_{c 0}+\frac{I T}{2 C}$ is larger than $I R_{s}$ by an order of magnitude or more, the charging efficiency can be over $90 \%$. The curved line that is illustrated in Fig. 2 represents the change of charging efficiency along with the charging current, where $R_{s}=25 \mathrm{~m} \Omega$ and $V_{c 0}+\frac{I T}{2 C}=25 \mathrm{~V}$. It is shown that the lower the charging current and the higher the supercapacitor initial voltage, hence the higher charging efficiency, meanwhile the charging speed is slower under constant current charging mode.

In constant power charging mode (CPCM), assuming the charging power is constant as $P_{i}$, the charging efficiency can be expressed as:

$$
\eta=\frac{E_{c}}{E_{t}}=\frac{\frac{1}{2} C\left(V_{c T}^{2}-V_{c 0}^{2}\right)}{P_{i} T} .
$$

From (1) and (2), the math equation between input power, supercapacitor voltage and current is as below:

$$
P_{i}=V_{c}(t) i(t)+i(t)^{2} R .
$$

So, the differential equation of supercapacitor voltage can be obtained as below:

$$
C V_{c}(t) \frac{d V_{c}(t)}{d t}+C\left(\frac{d V_{c}(t)}{d t}\right)^{2}-P_{i}=0 .
$$

When time $T$ is divided into $\mathrm{n}$ intervals of length $\Delta t_{n}$, assuming that in each stepping time, the charging current is constant, and supercapacitor voltage increases linearly, and the input voltage and the charging current meet $v_{i n}(t) i_{n}(t)=P_{i}$. According to this scheme, charging power of supercapacitor within 10 seconds is calculated by using Matlab, where supercapacitor voltage $V_{\mathrm{c} 0}=0$, the charging power $P_{\mathrm{i}}=50 \mathrm{~W}$, $R_{\mathrm{s}}=25 \mathrm{~m} \Omega$ and $C=55 \mathrm{~F}$. It is illustrated in Fig. 3 that the low supercapacitor voltage result in a very low charging efficiency in the initial charging period, because the power consumption almost consumed totally on ESR $R_{\mathrm{s}}$. However, if the total input power remains the constant, the power consumed on ESR would be decreased and the charging power on supercapacitor would be increased accordingly, and the charging efficiency would be finally up to a rate over $95 \%$.

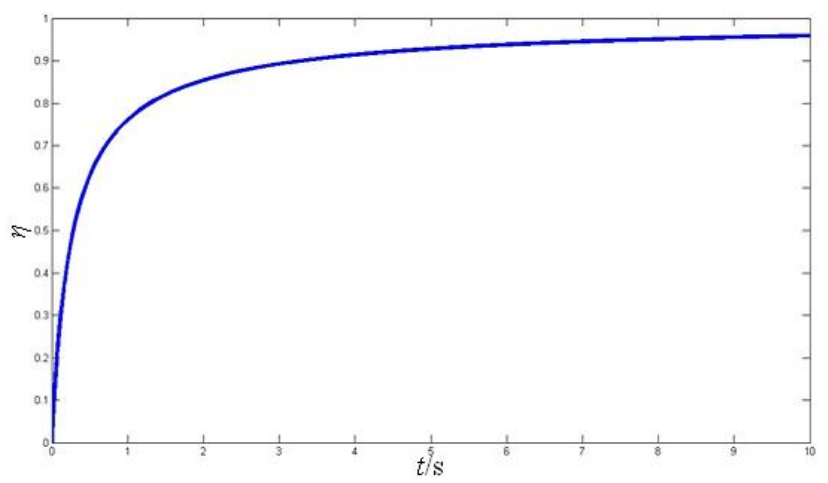

Figure 3. The charging efficiency under constant power charging mode

By way of tracking the maximum charging efficiency of each charging stage, the most efficient power transfer from PV cells to supercapacitor can be realized. The 10 charging stages are divided charging period according to the voltage ranging 
from $0 \mathrm{~V}$ to $60 \mathrm{~V}$ of supercapacitor module, i.e. $0 \mathrm{~V}-6 \mathrm{~V}, 6 \mathrm{~V}-12 \mathrm{~V}$, $12 \mathrm{~V}-18 \mathrm{~V}, 18 \mathrm{~V}-24 \mathrm{~V}, 24 \mathrm{~V}-30 \mathrm{~V}, 30 \mathrm{~V}-36 \mathrm{~V}, 36 \mathrm{~V}-42 \mathrm{~V}, 42 \mathrm{~V}-48 \mathrm{~V}$, $48 \mathrm{~V}-54 \mathrm{~V}, 54 \mathrm{~V}-60 \mathrm{~V}$. The appropriate charging mode for a charging stage can then be determined by calculating the charging efficiency in constant current charging mode (CCCM) and CPCM respectively for the stage. The charging efficiency in CCCM can be calculated by using (8), whereas the charging efficiency in CPCM can be obtained via piecewise linear approximation.

Where the maximum power of PV cells $P_{\text {gmax }}=100 \mathrm{~W}$, the supercapacitor value $C_{\mathrm{sc}}=55 \mathrm{~F}, \mathrm{ESR} R_{\mathrm{s}}=25 \mathrm{~m} \Omega$, and the nominal voltage of supercapacitor $V_{\mathrm{t}}=60 \mathrm{~V}$, at $0 \mathrm{~V}-6 \mathrm{~V}$ charging stage, based on (8), as $V_{\mathrm{c} 0}=0$, the charging efficiency in CCCM would be only related to the charging time $T$, as in

$$
\eta=\frac{\frac{I T}{2 C}}{I R_{s}+\frac{I T}{2 C}}=\frac{\frac{T}{2 \times 55}}{0.25+\frac{T}{2 \times 55}} .
$$

At $0 \mathrm{~V}-6 \mathrm{~V}$ charging stage, under the same light intensity and ambient temperature, assuming the power of PV cells is constant, the energy obtained by supercapacitor and generated by PV cells can be calculated respectively, as in

$$
\begin{gathered}
E_{s c}=\frac{1}{2} C\left({V_{c f}}^{2}-V_{c 0}{ }^{2}\right) . \\
E_{p v}=P_{g \max } T .
\end{gathered}
$$

Thus the charging efficiency would be:

$$
\eta^{\prime}=\frac{E_{s c}}{E_{p v}}=\frac{990}{100 T} .
$$

It is obvious that in (12) $\eta$ is an increasing function of the charging time $T$, while in (15) $\eta^{\prime}$ is a decreasing function. So there is higher charging efficiency, because as the charging current is decreased with the longer time the energy loss on ESR falls in CCCM. However, when supercapacitor is charged by PV cells, the increase of energy generated by PV cells with the charging time would result in a decrease of the charging efficiency, while the energy obtained and reserved by supercapacitor remains unchanged.

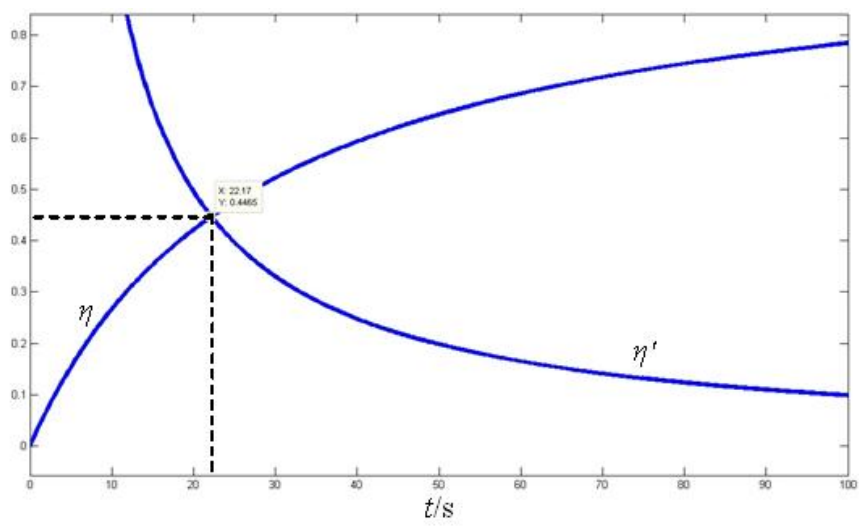

Figure 4. The charging efficiency in CCCM, at $0 \mathrm{~V}-6 \mathrm{~V}$ charging stage
The relationships of $\eta$ and $\eta^{\prime}$ with $T$ is shown in Fig.4 obtained from Matlab, where $T$ is set from 1 to 100 seconds. At timing $T=22.17 \mathrm{~s}$ while the curves of $\eta$ and $\eta^{\prime}$ cross each other, the charging efficiency is $44.65 \%$. Based on (6), at this point, the charging current $I=14.885 \mathrm{~A}$, which is the most optimal current.

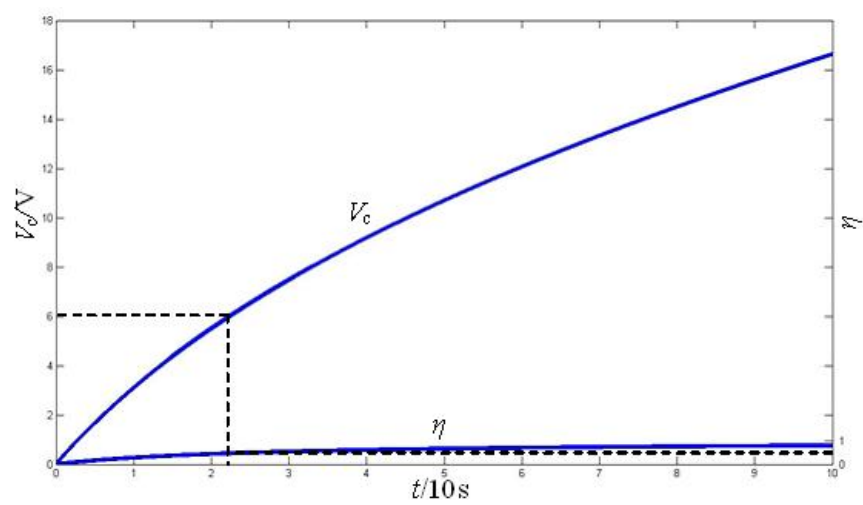

Figure 5. The charging efficiency and the supercapacitor voltage curve at $0 \mathrm{~V}-6 \mathrm{~V}$ charging stage

By using the method of piecewise linear approximation, the supercapacitor voltage and the charging efficiency in CPCM can be calculated. Assuming the power generated by PV cells is $100 \mathrm{~W}$ that is delivered to supercapacitor by the way of constant power delivery, the charging efficiency $\eta$ and the supercapacitor voltage $V_{\mathrm{c}}$ can be illustrated in Fig.5. At the point $T=22.392 \mathrm{~s}$, where $V_{c}$ arrives at $6 \mathrm{~V}$, the charging efficiency $\eta=44.21 \%$.

It is shown that, at $0 \mathrm{~V}-6 \mathrm{~V}$ charging stage, the charging efficiency of constant current charging mode is slightly higher than charging efficiency in CPCM. However, it is not a big difference, as at the beginning of this stage supercapacitor voltage is 0 , which leads to most of the power generated by PV cells to be consumed on ESR and the maximum charging efficiency to be limited to be less than $44 \%$.

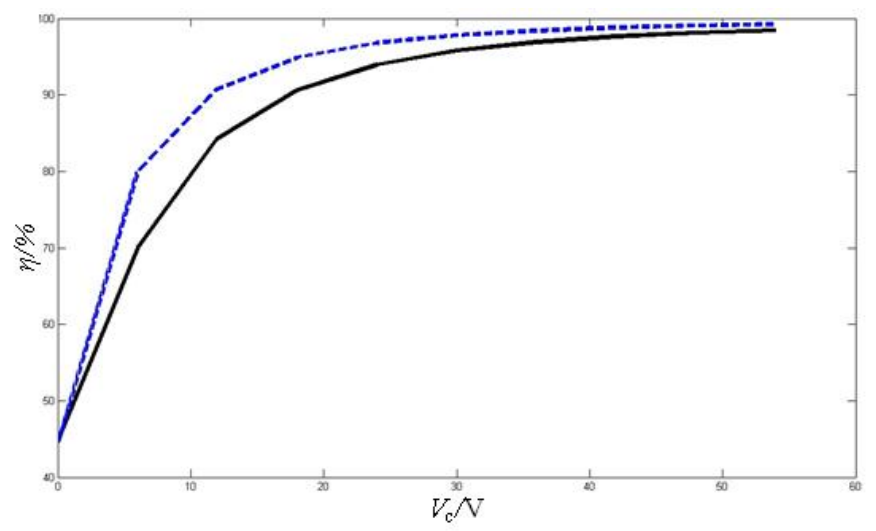

Figure 6. Comparison of charging efficiency in CCCM and CPCM

There is a comparison between the charging efficiency of supercapacitor charged by PV cells in the two modes, i.e. CCCM and CPCM, where the supercapacitor voltage rises 
from $0 \mathrm{~V}$ to $60 \mathrm{~V}$ in Fig.6. The dotted line represents the charging efficiency in CPCM, and the solid line represents the charging efficiency in CCCM. It is shown that the maximum charging efficiency in both modes increases with the rise of supercapacitor voltage, while the charging efficiency in CPCM is higher than the charging efficiency in CCCM at all the time.

It is seen that the CPCM is better than CCCM at all the charging period from the above comparisons of charging efficiency. Meanwhile, if the MPP is the tracking goal of the charging power using MPPT, the charging efficiency would be adjusted automatically with MPP. It's mean that when the power output from PV cells is larger, the charging efficiency will be lower, while when the power output falls, the charging efficiency will rise. But, the situation may be out of control as the power output from PV cells may not meet the power of the charging current in CCCM.

\section{CHARGING SYSTEM USING TWO-STAGE BUCK-BOOST CONVERTER}

Single-stage converter operated in MPPT control can only maximize power output from PV cells, but not control the power output from the converter. Therefore it cannot ensure the maximum energy to be delivered to supercapacitor.

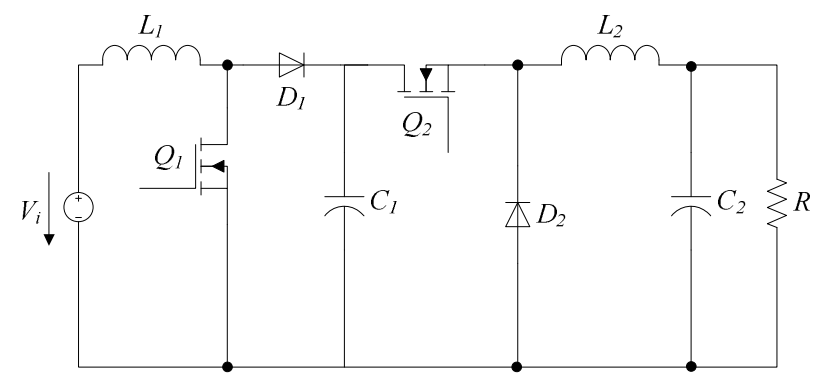

Figure 7. The two-stage Buck-Boost converter

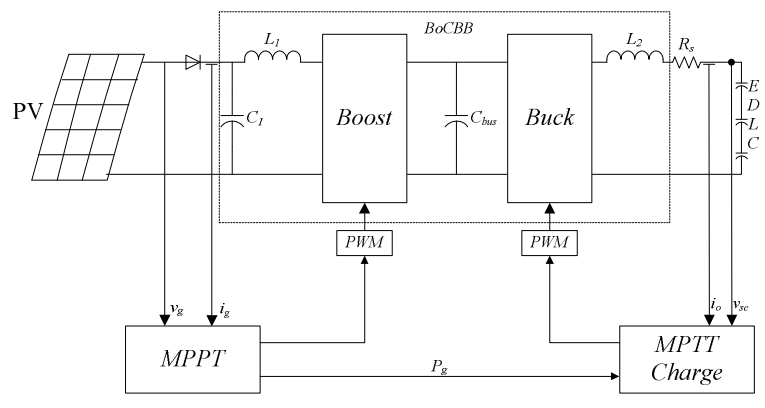

Figure 8. Charging circuit using BoCBB converter

The input voltage of PV cells may decreases with the change of temperature. The widely used solution is to cascade Boost converter with PV cells. There is a topology of two-stage Buck-Boost converter is presented in Fig.7 (BoCBB: Boost Cascaded Buck-Boost Converter) that front Boost circuit is cascaded to PV cells and Power generated from PV battery can be buffered through capacitor $C_{1}$ by using MPPT control. Then the back Buck circuit will reduce the voltage and deliver energy to supercapacitor according to the adopted charging strategy. Such topology is suitable to two-stage converters where supercapacitor is charged by PV cells.

There is a charging circuit that uses BoCBB converter to charge supercapacitor in Fig.8. Also, the MPPT controller is able to maximize the power output from PV cells by adjusting the equivalent impedance of converter and adjusting Boost duty cycle of BoCBB. The power can then be stored in $C_{\text {bus. }}$. By using MPPT control, and the back circuit will deliver safely as much energy stored in $C_{\text {bus }}$ to supercapacitor as possible.

\section{Simulation}

A simulation system where supercapacitor was charged by PV cells through two-stage Buck-Boost converter was built in Matlab/Simulink. The simulation parameters are shown, as in table I.

TABLE I. SIMULATION PARAMETERS

\begin{tabular}{|c|c|c|}
\hline Parameters & Meaning & Value \\
\hline$T$ & Ambient temperature of PV cells & $25^{\circ} \mathrm{C}$ \\
\hline$S$ & Light intensity & $400 \mathrm{~W} / \mathrm{m}^{2}$ \\
\hline$L_{\mathrm{g}}$ & Input inductance & $0.01 \mathrm{H}$ \\
\hline$L_{\mathrm{o}}$ & Output inductance & $0.02 \mathrm{H}$ \\
\hline$C_{\mathrm{d}}$ & DC capacity & $4000 \mathrm{uF}$ \\
\hline$R_{\mathrm{s}}$ & ESR of supercapacitor & $60 \mathrm{~m} \Omega$ \\
\hline$C$ & Capacity of supercapacitor & $1 \mathrm{~F}$ \\
\hline$f_{\mathrm{s}}$ & Switching frequency & $20 \mathrm{kHz}$ \\
\hline
\end{tabular}

Firstly, the circuit is simulated for 2 seconds under a constant light intensity of $400 \mathrm{~W} / \mathrm{m}^{2}$. There is Power output of PV cells in MPPT control in Fig. 9. It is demonstrated that the power output of PV cells is stable at $725 \mathrm{~W}$ after $0.1 \mathrm{~s}$.

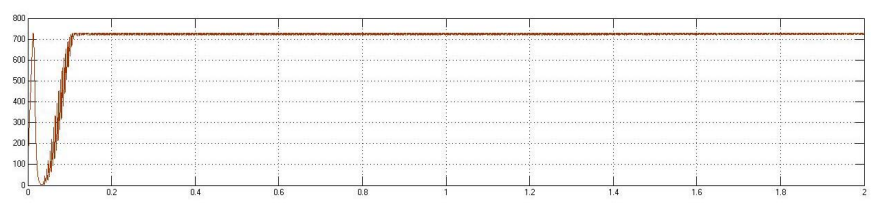

Figure 9. Power output of PV cells under MPPT control

The setting value of the charging efficiency of the circuit is assumed to be $90 \%$. It is illustrated in Fig. 10 that at the beginning charging period the charging efficiency is low, as part of the power is consumed on ESR because of the relatively low supercapacitor voltage. The charging power will be stable at $652 \mathrm{~W}$ after $0.5 \mathrm{~s}$. It is also shown that the charging efficiency after $0.1 \mathrm{~s}$ in Fig while the supercapacitor voltage arrives at $20 \%$ of that of $2 \mathrm{~s}$ and the charging efficiency is about $70 \%$. Along with the increase of the supercapacitor voltage, the charging efficiency can track the setting value of $90 \%$ accurately after $0.8 \mathrm{~s}$.

The supercapacitor voltage will gradually increase while the charging current will drops with time, thus the whole 
charging power can maintains the same. The charging current would be very high and arrive at a current peak in the initial charging period under constant power charging control, because the supercapacitor voltage is relative low. Therefore, it is adopted to limit the charging current at the beginning of charging, and when the supercapacitor voltage increases to a certain percent of the rated voltage, the constant power charging control can be adopted.
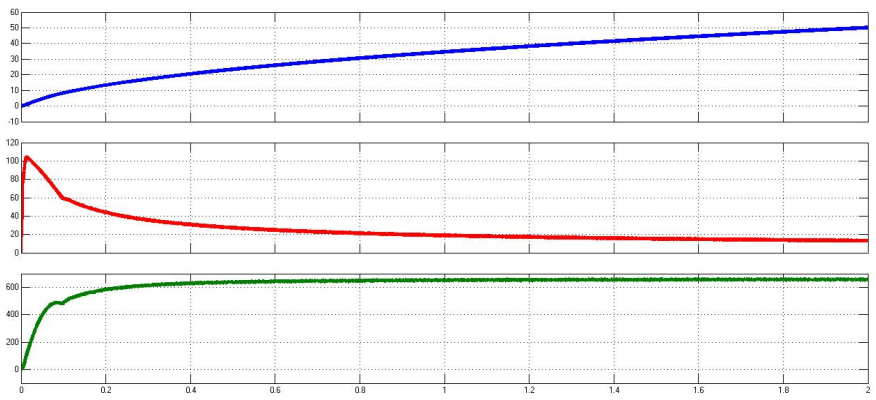

Figure 10. The supercapacitor voltage, the charging current and the charging efficiency under MPPT control

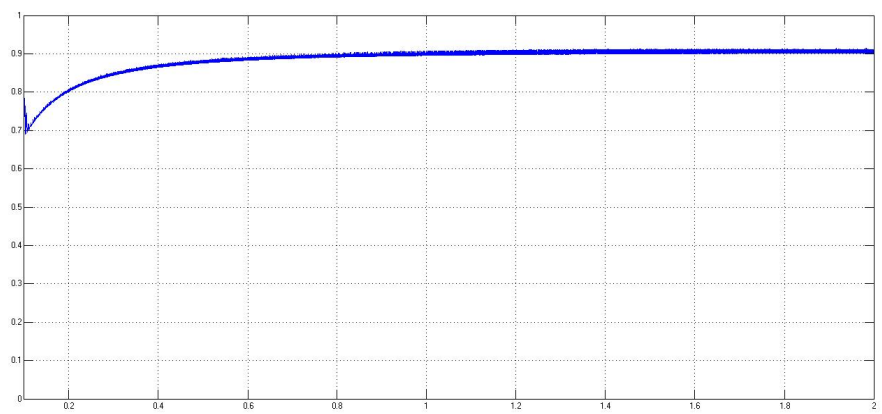

Figure 11. The charging efficiency of supercapacitor under constant power charging mode

\section{CONCLUSIONS}

By comparison, it is demonstrated that the constant power charging mode is better for charging supercapacitor. The twostage Buck-Boost converter have two stages, which allows the front-Buck circuit is able to let PV cells operate under MPPT control and simultaneously the post-Boost circuit is able to let supercapacitor operate under the constant power charging mode by tracking the charging current. The simulation showed that it can effectively ensure the charging efficiency of the system.

\section{ACKNOWLEDGMENT}

This work is supported by Beijing Municipal Commission of education science and technology plan projects (No. KM201010772010), (No. KM201010772009), Funding Project for Academic Human Resources Development in Institutions of Higher Learning Under the Jurisdiction of Beijing Municipality (No.PHR201108262) and Funding Project for Academic Human Resources Development in Institutions of Higher Learning Under the Jurisdiction of Beijing Municipality(PHR201007130).

\section{REFERENCES}

[1] Brunelli D, Moser C, Thiele L, Benini L. Design of a Solar-Harvesting Circuit for Batteryless Embedded Systems[J]. IEEE Transactions on Circuits and Systems I: Regular Papers, 2009, 56(11): 2519-2528

[2] Glavin E, Chan W, Armstrong S, Hurley G. A stand-alone photovoltaic supercapacitor battery hybrid energy storage system[C]. EPE-PEMC 2008, 2008: 1688-1695

[3] Hyo-Ryong Seo, Gyeong-Hun Kim, Sang-Yong Kim, et al. Power quality control strategy for grid-connected renewable energy sources using PV array and supercapacitor[C]. ICEMS 2010, 2010: 437-411

[4] Chad Abbey, Géza Joos. Supercapacitor Energy Storage for Wind Energy Applications[J]. IEEE Transactions on Industrial Applications, 2007, 43(3): 769-776

[5] Haihua Zhou, Bhattacharya T, Duong Tran, et al. Composite Energy Storage System Involving Battery and Ultracapacitor With Dynamic Energy Management in Microgrid Applications[J]. IEEE Transactions on Power Electronics, 2011, 26(3): 923-930

[6] Jisung Lee, Sangkwon Jeong, Young Hee Han, et al. Concept of Cold Energy Storage for Superconducting Flywheel Energy Storage System[J]. 2011, 21(3): 2221-2224

[7] Chiang, S.J., Hsin-Jang Shieh, Ming-Chieh Chen. Residential Photovoltaic Energy Storage system[J]. IEEE Transactions on Industrial Electronics, 1998, 56(11): 385-394

[8] Carrasco J M, Franquelo L G, Bialasiewicz J T, et al. Power-electronic systems for the grid integration of renewable energy sources: a survey [J]. IEEE Transactions on Industrial Electronics, 2006, 53(4): 1002-1016

[9] Kim Younghyun, Chang Naehyuck, Wang Yanzhi, et al. Maximum power transfer tracking for a photovoltaic-supercapacitor energy system[C]. IEEE ISLPED 2010, 2010: 307-312

[10] Nobuyoshi Mutoh, Takayoshi Inoue. A Control Method to Charge Series-Connected Ultraelectric Double-Layer Capacitors Suitable for Photovoltaic Generation Systems Combining MPPT Control Method [J]. IEEE Transactions on Industrial Electronics. 2007, 54(1): 374-383

[11] R Kim, J Lai. A seamless mode transfer maximum power point tracking controller for thermoelectric generator applications[C]. IEEE IAS '07, 2007: 977-984

[12] Y Nozaki, K Akiyama, H Kawaguchi, et al. An improved method for controlling an EDLC-battery hybrid stand-alone photovoltaic power system[C]. IEEE APEC 2000, 2000: 781-786 